\title{
The use of the self-management plan system of care in adult asthma
}

\author{
Shaun Holt ${ }^{a}$, Matthew Masoli ${ }^{b}$, Richard Beasley ${ }^{b, c, *}$
}

\author{
a P3Research, Wellington, New Zealand \\ ${ }^{b}$ Medical Research Institute of New Zealand, 3rd Floor, 99 The Terrace, P.O. Box 10055, \\ Wellington 6001, New Zealand \\ c University of Southampton, Southampton, UK
}

\section{KEYWORDS \\ Asthma \\ self-management plans; \\ Asthma action plans; \\ Asthma management}

\begin{abstract}
Summary The development of self-management plans arose as clinicians tried to design better methods by which they could deliver asthma care and reduce the significant mortality and morbidity associated with this disease. The basic principles that resulted have been widely endorsed, and self-management plans are now recommended in the long-term management of adult asthma. Self-management plans essentially focus on the early recognition of unstable or deteriorating asthma, by monitoring peak flow or symptoms. Through the use of written guidelines, patients are then able to determine when it is necessary to adjust therapy or obtain medical assistance.

There is now convincing evidence that the use of self-management plans by patients with asthma leads to a marked reduction in morbidity and a reduced requirement for acute medical treatment including hospital admissions. Recent research has also clarified many of the different issues concerning their structure and implementation. In some respects the skill in the use of the asthma self-management plan system of care is the ability to modify the standard plans to meet the particular needs of the individual asthmatic patient, including their preferences.
\end{abstract}

(c) 2003 General Practice Airways Group. Published by Elsevier Ltd. All rights reserved.

\section{Introduction right General Prac}

It is intriguing to reflect that the first pilot study of an asthma self-management plan was published less than 15 years ago [1]. Since then this system of care has become widely accepted, such that national and international guidelines currently recommend this approach in the long-term management of adult asthma [2-4]. This acceptance has been based on the demonstration of the effi-

\footnotetext{
${ }^{*}$ Corresponding author. Tel.: +64-4-472-9199; fax: +64-4-472-9224.

E-mail address: richard.beasley@mrinz.ac.nz (R. Beasley).
}

cacy of this system of care, a better understanding of the groups "of asthmatics who might benefit most from their use, and determination of the key components of the different plans that have been used. In this report we review 12 issues relevant to the asthma self-management plan system of care which provide the basic knowledge required for its optimal use in primary care.

\section{Basic principles}

The term asthma self-management plan system of care refers to the process whereby individual 
Table 1 The basic principles of adult asthma self-management.

1. The need for objective self-assessment of asthma severity, with the educated interpretation of key symptoms and peak flow recordings

2. The use of regular inhaled corticosteroids and "as required" beta agonists for the long-term treatment of asthma; the use of systemic corticosteroids, high dose inhaled beta agonists, and medical review for severe asthma

3. The integration of self-assessment and self-management with written guidelines for both the long-term treatment of asthma and the treatment of acute severe asthma

asthmatic patients make changes to their treatment in response to the recognition of changes in the severity of their asthma in accordance with predetermined guidelines. As a result, this process involves the integration of self-assessment and self-management and incorporates written guidelines for both the long-term treatment of asthma and the treatment of severe asthma attacks, as summarised in Table 1.

\section{Standard prototype plan}

The standard asthma self-management plan based on the above principles is shown in Table 2. The first two stages provide guidelines for the regular long-term treatment of asthma. The instruction to vary the dosage of inhaled corticosteroid treatment in a stepwise manner in accordance with changes in asthma severity is supported by evidence that this approach is effective and can be followed without difficulty by asthmatic patients [5]. The third and fourth stages provide guidelines for the patient to recognise the development of severe asthma and to start intensive treatment in an attempt to prevent a life-threatening attack. Thus, self-management plans can be considered to provide practical guidelines in which the recommendations for acute se- vere and chronic persistent asthma can be brought together within the framework of one system. The basic structure of this standardised prototype plan has been used in most studies which have assessed the efficacy of this form of care [1,6-13].

\section{Different versions available}

Modified versions of the above prototype plan have been widely promoted by a number of organisations including the National Asthma Campaign (UK) (Fig. 1), and the New Zealand Asthma and Respiratory Foundation (Fig. 2). These systems include both a detailed and brief (credit card) version of the four step management plan outlined in Table 2. The detailed version provides considerable information for the patient with respect to guidelines for recognising deteriorating asthma and the appropriate therapeutic responses. No fixed peak flow percentages are recommended, to enable doctors to vary the levels at each stage for which treatment guidelines are made according to the requirements of individual patients. The "credit card" version of the plan has been designed to provide a "simple reminder" which can be carried by the patient or kept with a peak flow meter.

Table 2 Adult asthma self-management plan: what to do and when.

\begin{tabular}{llll}
\hline Step & Peak flow & Symptoms & Action \\
\hline 1 & $80-100 \%$ best & Intermittent/few & $\begin{array}{l}\text { Continue regular inhaled } \\
\text { corticosteroids; use inhaled beta } \\
\text { agonist for relief of symptoms } \\
\text { Increase the dose of inhaled } \\
\text { corticosteroid or start if not currently } \\
\text { taking }\end{array}$ \\
3 & $<80 \%-85 \%$ best & $\begin{array}{l}\text { Waking at night with asthma; } \\
\text { increasing } \beta \text {-agonist use }\end{array}$ & $\begin{array}{l}\text { Start oral corticosteroids and contact } \\
\text { a doctor } \\
\text { Call emergency doctor or ambulance } \\
\text { urgently }\end{array}$ \\
\hline
\end{tabular}

At all stages, take inhaled beta agonist for relief of symptoms. 


\section{For your doctor or nurse to complete}

\section{Zone 1}

Your asthma is under control if:

- Your peak flow readings are above

and

- it does not disturb your sleep and

- it does not restrict your activities

\section{Action}

Continue your normal medicines

For your doctor to complete

\section{Zone 3}

Your asthma is severe if:

- Your peak flow readings have

fallen to between and

- You are getting increasingly breathless

- You are needing to use your

(reliever inhaler) every hours or more often
Action

Ring your doctor or nurse

- Take_ prednisolone (steroid) tablets ( $\mathrm{mg}$ each) and then

- Discuss with your doctor how to stop taking the tablets

- Continue to take your

(reliever and preventer inhalers) as required

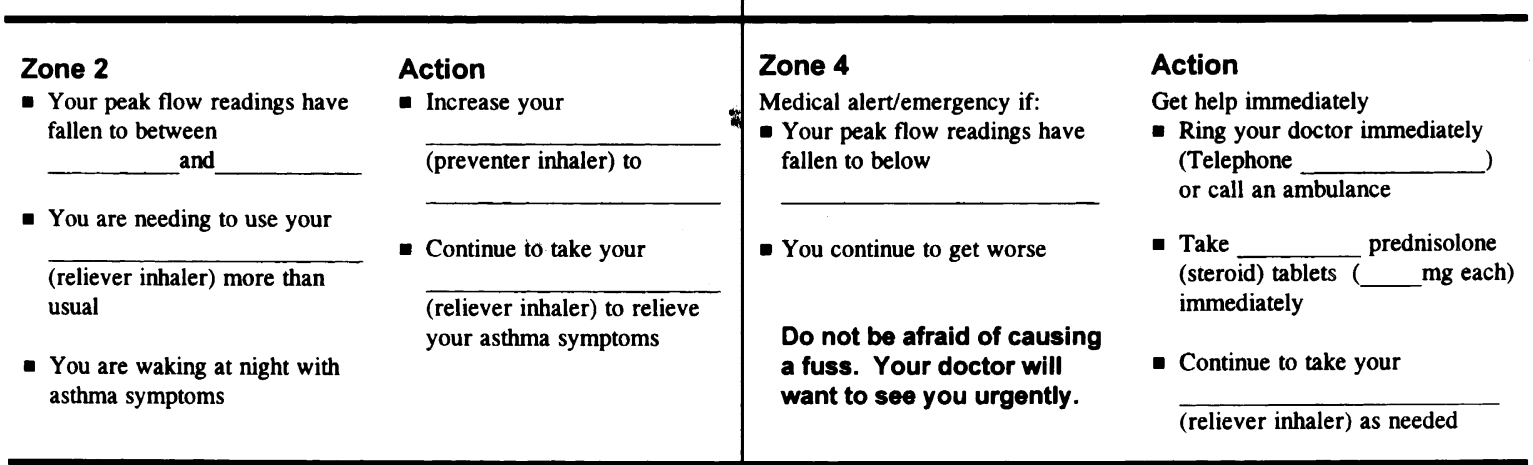

\section{Notes}

\section{Your own asthma management plan}

This plan helps you to adjust your treatment according to the measurements on your peak flow chart. If you take quick action, you can usually prevent severe attacks.

These instructions are only a guide, so you and your doctor or nurse may need to change them. Although the plan has four 'zones', some doctors prefer to use three and may wish you to leave out Zone 2.

Your doctor will write the ranges of peak flow which relate to each action below.

Your best (target) peak flow is

\section{Update your management plan}

- Because your asthma may change as time goes by, your doctor may need to change your plan accordingly. You should visit your doctor or nurse at least twice a year.

- If you often find yourself in Zones 2 or 3, let your doctor know because your medicines may need to be increased or changed.

- If you are in Zone 1 all the time, it may be possible for your doctor to reduce your medicines.

- We recommend that a month or so after you start your selfmanagement plan you should review it with your doctor or nurse.

The mini asthma-management plan

You might find it helpful to carry this 'credit card' version of your plan with you at all times. It can act as a reminder in case you have unexpected symptoms.
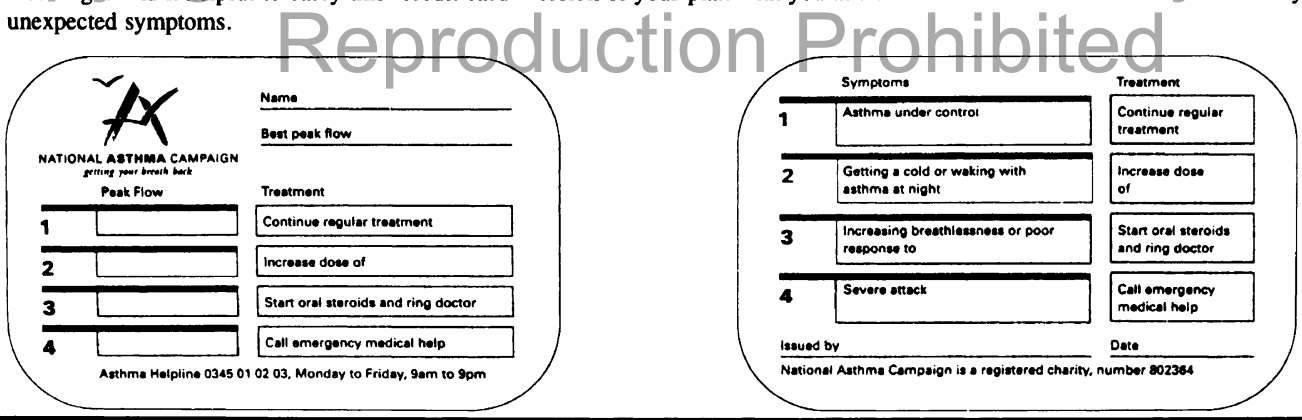

Figure 1 Asthma self-management plan promoted by National Asthma Campaign (UK). Booklet 7: "self-management and peak flow measurement"'. 


\section{Asthma Self Management Plan Instructions}

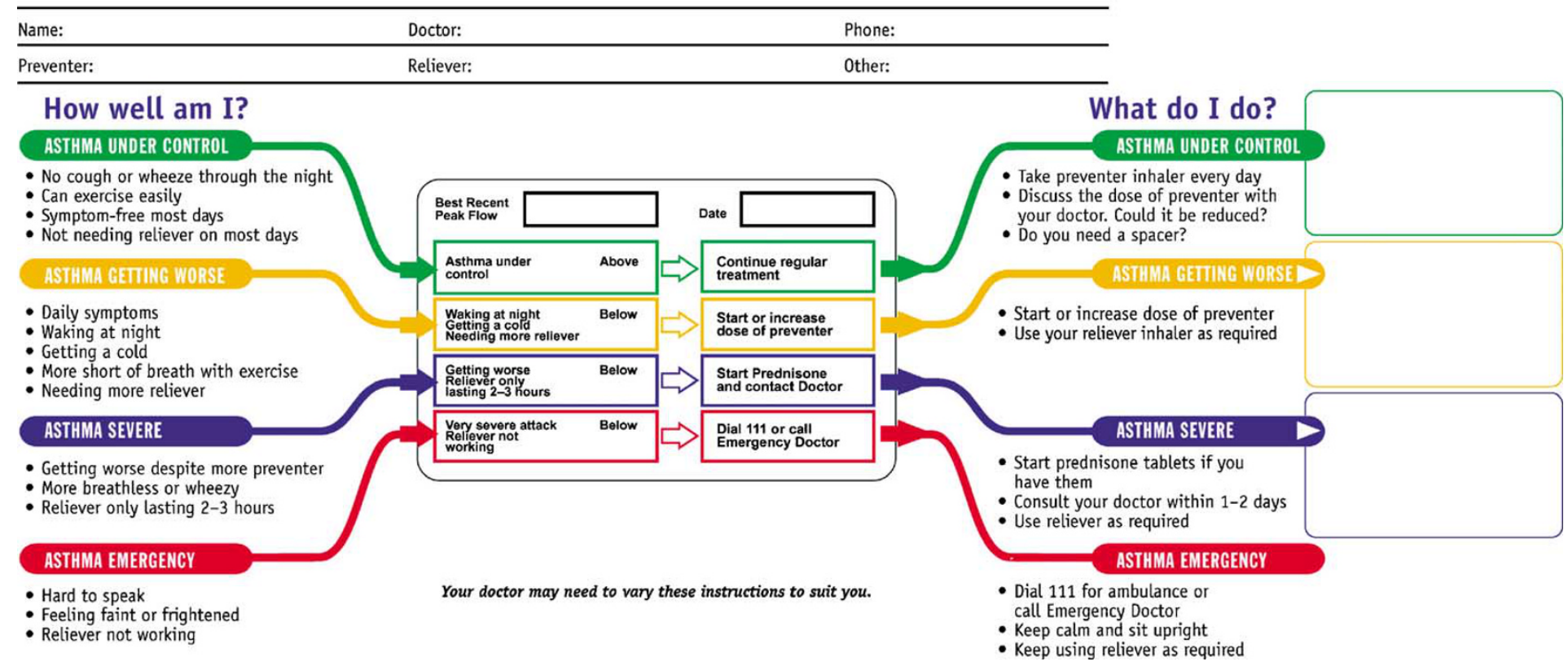

Figure 2 The New Zealand Asthma and Respiratory Foundation asthma self-management plan.

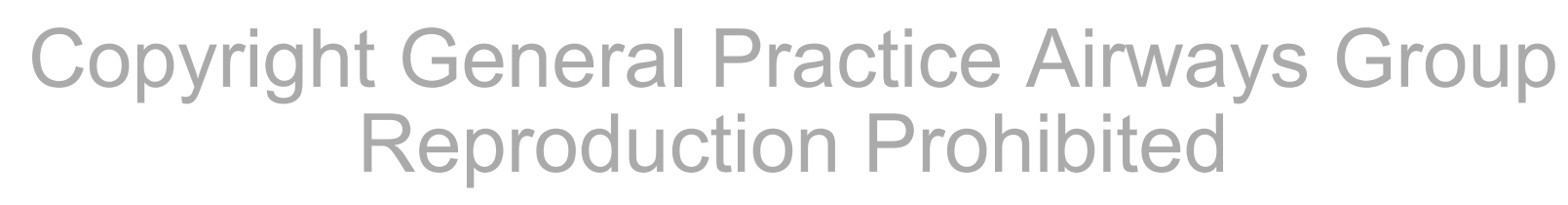




\section{Individual patient requirements}

In providing these specific plans it needs to be stressed that the requirements of individual asthmatic patients will vary considerably and as a result no single plan is likely to be suitable for every patient. Certain features may need to be varied, depending on the needs of the patient for whom the plan is developed. These features include the amount of detail provided, the number of stages used, the specific drug treatment recommended at each stage, and the precise level (or range of levels) of peak flow (whether pre- or post-bronchodilator) at which patients are advised to modify therapy or seek medical assistance. Many of these issues are discussed below. In some respects the skill in their use is the ability to modify the standard plans to meet the particular needs of the individual asthmatic patients, including their preferences.

\section{Peak flow levels}

Several different levels of peak flow have been used to designate the different stages of asthma severity. For example, in the situation of severe asthma requiring oral steroids and medical review, values ranging from 50 to $70 \%$ of personal best or predicted peak flow have been recommended [1,6-10,12,13]. While the use of personal best, rather than predicted peak flow levels is now recognised as preferable for reference values, the absolute percentage levels to be used at each stage remain uncertain [14].

This uncertainty includes whether the lowest value on a single day should be used or a certain value over two consecutive days; whether the peak flow values should be pre- or post-bronchodilator; and whether values should be restricted to a certain time of day such as in the morning. With respect to the number of days, it has been shown that similar changes in treatment result from the use of $60 \%$ of personal best on 2 days when compared with $50 \%$ of personal best on 1 day, taking into account the time of day and prior use of medication [14]. This study also suggests that pre-bronchodilator morning peak flows were the most sensitive measure of asthma control, although in the situation of severe asthma requiring the frequent use of beta agonist therapy, it is not possible to obtain pre-bronchodilator peak flow recordings. Likewise in the situation of severe asthma it may be necessary to measure the peak flow repeatedly during a $24 \mathrm{~h}$ period, rather than limit the measurements to a single morning recording.
One approach which addresses many of these issues is to recommend pre-bronchodilator morning peak flow recordings as a routine, with comparisons being made with the best previously achieved morning pre-bronchodilator value. The frequency of recordings would then be increased in the situation of severe asthma. Rather than set a single level at each stage of severity, a range of peak flow values is provided at each level; for example, for severe asthma requiring medical review and oral steroids, the patient recognises this stage when the peak flow falls to less than $70 \%$ of previous best, and should have taken action before the peak flow falls to $60 \%$ of best (Table 2 ).

\section{Peak flow versus symptoms (or both?)}

Similar efficacy has been demonstrated with the use of "symptoms only" compared with "peak flow only" plans, in terms of the proportion of subjects requiring unscheduled visits to the doctor, emergency room treatment or hospital admission $[13,15]$. This would suggest that either system of monitoring may be used to enable patients to recognise poor asthma control. However, there is data to indicate that in the situation of an attack of asthma, most patients prefer the use of both the peak flow and symptoms, rather than one means of monitoring their control [9]. This would suggest that patients should be offered both peak flow and symptom-based methods of assessment if feasible.

\section{Which components of the plan contribute to its efficacy?}

It has been difficult to determine which components of the plan lead to the clinical improvement, as the different features of the plan are so closely related. The evidence to date suggests that it is likely that the clinical efficacy is due to improved compliance, which is a result of the close integration of self-assessment with treatment. In support of this view, the Finnish study reported that similar doses of inhaled corticosteroids were prescribed before and after the introduction of the self-management system, despite a marked improvement in asthma control resulting from the use of the plan over a 12-month period [6]. This would suggest that the improvement in morbidity observed was primarily related to improved compliance, rather than an increased prescribed dose of inhaled corticosteroid therapy. This interpretation is supported by the Norwegian study in which the use of a guided self-management plan system of care resulted in 
a marked improvement in compliance with inhaled corticosteroid therapy [16]. Utilising a measure of corticosteroid inhaler compliance based on the ratio of dispensed to prescribed therapy over a 12 -month period, the median compliance in the self-management group was $82 \%$ compared with $55 \%$ in the control group. This greater level of compliance was associated with an improved clinical outcome [11] and was cost-effective [17].

In other studies, there was data to suggest that the patient's self-assessment of asthma severity has enabled determination of the required dose of inhaled corticosteroid therapy. This view is supported by the observation that patients enrolled in a number of the studies were previously taking inhaled corticosteroids and that with regular assessment as a result of the use of a management plan, their inhaled corticosteroid dose was appropriately increased, with a resulting improvement in asthma control $[1,7,12]$.

\section{Amount of detail}

Patients with asthma prefer simpler as opposed to more detailed plans. This is illustrated by the series of the studies of the use of the credit card plan, which provides simple management guidelines based on the assessment of asthma severity, printed on a small plastic card the size of a credit card. In these studies the participants expressed a preference that the plan should not be bigger or present more detail, suggesting that complicated plans may not necessarily be suitable for general use $[9,18]$. Indeed there is a need for the development of simpler plans including two stage plans which provide simple instructions on when the patient should seek urgent medical care in the situation of a severe exacerbation of asthma.

\section{How are plan'sysed by patients? al Pra}

It has been possible to obtain some understanding of how patients use their self-management plans from some of the published studies. In the 12-month Finnish study of a standard prototype plan, the instruction to double the dose of inhaled corticosteroid when the peak flow fell to $<85 \%$ was followed on $62 \%$ of occasions [6]. On most of these occasions, the inhaled corticosteroid was increased during the first day on which the peak flow values fell, and the patients maintained the higher dose for at least 1 week. After doubling the inhaled corticosteroid, the peak flow values slowly returned towards the previous level, followed by a later im- provement in symptoms. With respect to the instruction to start oral corticosteroids when the peak flow fell to $<70 \%$, this was followed on $77 \%$ of occasions. Interestingly, adherence to self-management instructions was strongly related to the severity of symptoms of asthma, with a 29, 61, 79 and 100\% adherence with associated symptom scores of 0,1 , 2 and 3 , respectively.

In one of the studies of the "credit card" plan undertaken 2 years after the initial clinical trial was completed, only $35 \%$ of patients reported that they monitored their peak flows more than once a week when stable, whereas $81 \%$ recorded their peak flows during a severe attack [18]. The corresponding proportion of patients who referred to their plans in these situations was 13 and 58\%, respectively.

\section{Incorporation of other medications}

The currently used asthma self-management plans were developed at a time when inhaled corticosteroids and short-acting beta agonist drugs were the standard medications used in the routine long-term management of asthma. Since then long-acting beta agonist drugs have been increasingly used, administered together with inhaled corticosteroids either as separate inhalers or from combination devices. As a result long-acting beta agonist drugs are now recommended at Step 3 of the guidelines when asthma is not adequately controlled with inhaled corticosteroids in doses between 200 and $1000 \mu \mathrm{g}$ per day of BDP or equivalent [2-4].

Recently a prototype asthma self-management plan system of care has been developed with the combination budesonide/formoterol inhaler (Symbicort) as outlined in Table 3. The abstract of a study investigating this system suggested that it had a similar efficacy to the standard regime in which a fixed dose of Symbicort (two puffs twice daily) was used [19]./ From this preliminary data it can be deduced that the benefits of an asthma self-management 'plan incorporating long-acting beta agonists may not be as substantial as the traditional regimes; alternatively it could be suggested that the use of a long-acting beta agonist does not preclude the use of this self-management plan system of care.

\section{Efficacy}

Despite the consensus on both the necessity and the principles underlying the development of asthma self-management plans, it is only recently that 
Table 3 Management plan incorporating adjustable dosing of combination inhaled corticosteroid/long-acting beta agonist inhaler ${ }^{\mathrm{a}}$.

\begin{tabular}{|c|c|c|}
\hline & $\begin{array}{l}\text { Adjustment } \\
\text { (inhalations bd) }\end{array}$ & Criteria \\
\hline $\begin{array}{l}\text { Initial step down (judged by the } \\
\text { investigator) }\end{array}$ & 2 to 1 & $\begin{array}{l}\text { Patient felt asthma well controlled and in the } \\
\text { previous } 7 \text { days had met both of the following: } \\
\text { Reliever medication } \leq 2 \text { times } \\
\text { No night-time awakening due to asthma }\end{array}$ \\
\hline Step up (judged by the patient) & 1 to 4 & $\begin{array}{l}\text { Two consecutive days/nights with: } \\
\text { Reliever medication used } \geq 3 \text { times during day, or } \\
\text { Night-time awakening due to asthma, or } \\
\text { Morning PEF }<85 \% \text { mean baseline value }\end{array}$ \\
\hline $\begin{array}{l}\text { Step down after } 7 \text { or } 14 \text { days of } \\
\text { step-up treatment (judged by } \\
\text { the patient) }\end{array}$ & 4 to 1 & $\begin{array}{l}\text { Last two consecutive days/nights with: } \\
\text { No more asthma symptoms than before the } \\
\text { worsening, as judged by the patient, and } \\
\text { No reliever medication used, and } \\
\text { No night-time wakening due to asthma, and } \\
\text { Morning PEF } \geq 85 \% \text { mean baseline value }\end{array}$ \\
\hline
\end{tabular}

PEF: peak expiratory flow.

a Symbicort: budesonide/formoterol combination inhaler.

their efficacy has been clearly established. The best assessment of their efficacy can be obtained from the recent systematic review of 24 randomised controlled trials of asthma self-management and education [20]. The meta-analysis of these studies identified that written action plans led to a reduction in hospitalisation for asthma, requirement for emergency room visits and nocturnal asthma. The impressive feature of this analysis was the magnitude of the improvement, with, for example, the risk of being hospitalised being reduced by over 40\% (Table 4). In addition, there is recent evidence that the use of a self-management plan system of care reduces the risk of mortality $[21,22]$. These findings form the basis for the recommendation that asthma self-management plans are used in the management of adult asthma, representing an optimal system of care. It shoutd be noted however that for the maximum benefit of this approach

Table 4 Relative risk of requirement of medical services and morbidity with the use of asthma self-management plan system of care.

\begin{tabular}{lll}
\hline & Odds ratio & $95 \% \mathrm{Cl}$ \\
\hline Hospital admission & 0.58 & $\mathrm{n} / \mathrm{a}$ \\
Emergency room visits & 0.55 & $0.39-0.77$ \\
Unscheduled doctor visits & 0.57 & $0.40-0.32$ \\
Days off work & 0.55 & $0.35-0.79$ \\
Nocturnal asthma & 0.53 & $0.39-0.72$ \\
\hline
\end{tabular}

to be maintained long-term, regular follow-up is required [23].

\section{Benefits for specific patient groups}

There is emerging evidence to suggest that certain asthmatics may benefit more than others from this system of care. In particular, it is recognised that the greatest benefit is likely to be obtained in patients with chronic severe asthma, and that compliance is likely to be a major problem in patients with mild asthma. This is reflected in patterns of use in countries such as Australia, where the use of management plans has been strongly promoted in clinical practice, and where around three in eight adult patients with mild asthma have an action plan, increasing to five in eight with severe asthma [24]. The following serves as a guide for the use of self-management ptans according to asthma severity.

In mild asthma, an initial period of assessment with recording of asthma symptoms and peak flow rates is recommended, to educate the patient to recognise changes in asthma severity, to identify those with a poor perception of asthma severity, to determine the best recorded peak flow values, and to monitor the response to the introduction of prophylactic therapy. Following this initial period, it would be possible to develop an asthma self-management plan which provides patients with simple written instructions as to when 
to seek medical help in the situation of a severe asthma attack. The regular use of a more detailed self-management plan is not recommended at this stage, as it is unlikely to lead to a major improvement in asthma control [25]. Furthermore, it is unlikely to be undertaken by the patient, even if recommended. An alternative approach is for patients with mild asthma to have a simple regimen in which the dose of inhaled corticosteroid therapy is adjusted by the physician at clinic visits, an approach which may be easier to follow [26].

In patients with moderate to severe asthma, a similar period of assessment is recommended for the same reasons as in mild asthma, and to allow for the development of a more detailed three or four stage asthma self-management plan. It is recommended that the amount of detail included will depend on the requirements of the patient and the degree of medical supervision that is deemed to be necessary. Patients should be advised to use the plan preferentially during periods of unstable asthma rather than during periods of good control. Patients who are identified as being poor perceivers of asthma severity on the basis of symptoms alone are particularly encouraged to use such a self-management plan system of care.

For patients with high risk asthma, for example, those with a recent hospital admission or known brittle asthma, the regular use of peak flow monitoring and recording of symptoms in association with an asthma self-management plan can be recommended, together with intensive medical and nursing supervision.

Finally, mention should be made of the evidence that the implementation of this system of care does not necessarily need to be undertaken by a medical practitioner. There are now a number of studies which indicate that primary responsibility for the introduction and supervision of this system can be undertaken by a nurse practitioner, working in partnership with a medical practitioner $[11,13,27]$. This iltustrates that whatever plan is employed, it needs to reflect the medical practice, resources and health care system of the community in which it is introduced and must be tailored to meet the specific needs of individual patients.

\section{References}

[1] Beasley R, Cushley M, Holgate ST. A self-management plan in the treatment of adult asthma. Thorax 1989;44:200-4.

[2] Global Initiative for Asthma. Global strategy for asthma management and prevention NHLBI/WHO Workshop Report. National Institutes of Health, National Heart, Lung and Blood Institute; 1996.
[3] British guideline on the management of asthma. Thorax 2003;58(Suppl 1):1-83.

[4] National Asthma Council Australia. Asthma management handbook. Melbourne: National Asthma Council Australia Ltd; 2002.

[5] Foresi A, Morelli MC, Catena E on behalf of the Italian Study Group. Low-dose budesonide with the addition of an increased dose during exacerbations is effective in long-term asthma control. Chest 2000;117:440-6.

[6] Lahdensuo A, Haahtela T, Herrala J, Kava T, Kiviranta K, Kuusista $P$, et al. Randomised comparison of guided self-management and traditional treatment of asthma over one year. BMJ 1996;312:748-52.

[7] Ignacio-Garcia JM, Gonzalez-Santos P. Asthma self-management education program by home monitoring of peak expiratory flow. Am J Respir Crit Care Med 1995;151: 353-9.

[8] Cowie RL, Revitt SG, Underwood MF, Field SK. The effect of a peak flow-based action plan in the prevention of exacerbations of asthma. Chest 1997;112:1534-8.

[9] D'Souza W, Crane J, Burgess C, Te Karu H, Fox C, Harper $M$, et al. Community-based asthma care: trial of a ". credit card"' asthma self-management plan. Eur Respir J 1994;7:1260-5.

[10] Thoonen BPA, Schermer TRJ, van den Boom G, Molema $\mathrm{J}$, Folgering $\mathrm{H}$, Akkermans RP, et al. Self-management of asthma in general practice. Thorax 2003;58:30-6.

[11] Gallefoss F, Bakke PS, Rsgaard PK. Quality of life assessment after patient education in a randomized controlled study on asthma and chronic obstructive pulmonary disease. Am J Respir Crit Care Med 1999;159:812-7.

[12] Turner MO, Taylor D, Bennett R, Fitzgerald JM. A randomized trial comparing peak expiratory flow and symptom self-management plans for patients with asthma attending a primary care clinic. Am J Respir Crit Care Med 1998;158:540-6.

[13] Charlton I, Charlton G, Broomfield J, Mullee MA. Evaluation of peak flow and symptoms only self-management plans for control of asthma in general practice. BMJ 1990;301: 1355-9.

[14] Douma WR, Kerstjens HAM, Rooyackers JM, Koëter GH, Postma DS. Dutch CNSLD Study Group. Risk of over-treatment with current peak flow criteria in self-management plans. Eur Respir J 1998;12:848-52.

[15] Powell H, Gibson PG. Options for self-management education for adults with asthma (Cochrane Review). In: Cochrane Library, issue 1. Oxford: Update Software; 2003.

[16] Gallefoss F, Bakke PS. How does patient education and - self-management among asthmatics and patients with chronic obstructive pulmonary disease affect medication? Am J Respir Crit Care Med 1999;160:2000-5.

[17] Gallefoss F, Bakke PS. Cost-effectiveness of self-management in asthmatics: a 1-year follow-up randomized, controlled trial. Eur Respir J 2001;17:206-13.

[18] D'Souza WJ, Te Karu H, Fox C, Harper M, Gemmell T, Ngatuere $M$, et al. Long-term reduction in asthma morbidity following an asthma self-management programme. Eur Respir J 1998;11:611-6.

[19] Ställberg B, Olsson P, Ekström T, Lindarck N. Adjustable dosing with budesonide/formoterol in a single inhaler (Symbicort ${ }^{\circledR}$ ) reduces exacerbations versus fixed dosing. Am J Respir Crit Care Med 2003;167(7): A894.

[20] Gibson PG, Coughlan J, Wilson AJ, Abramson M, Bauman $A$, Hensley MJ, et al. Self-management education and regular practitioner review for adults with asthma. The 
Cochrane Database of Systematic Reviews, vol. (issue 2). The Cochrane Library; 2002.

[21] Abramson MJ, Bailey MJ, Couper FJ, Driver JS, Drummer $\mathrm{OH}$, Forbes $\mathrm{AB}$, et al. and the Victorian Asthma Mortality Study Group. Are asthma medications and management related to deaths from asthma? Am J Respir Crit Care Med 2001;163:12-8.

[22] Beasley R, Crane J. Reducing asthma mortality with the asthma self-management plan system of care. Am J Respir Crit Care Med 2001;163:3-4 [Editorial].

[23] Ignacio-Garcia J-M, Pinto-Tenorio M, Chocrón-Giraldez MJ, Cabello-Rueda F, López-Cozar Al, de Ramón-Garrido E. Benefits at 3 years of an asthma education programme coupled with regular reinforcement. Eur Respir J 2002;20:1095101.
[24] Beilby JJ, Wakefield MA, Ruffin RE. Reported use of asthma management plans in South Australia. MJA 1997;166:298301.

[25] Jones KP, Mullee MA, Middleton M, Chapman E, Holgate Stand the British Thoracic Society Research Committee. Peak flow based asthma self-management: a randomised controlled study in general practice. Thorax 1995;50: 851-7.

[26] Ayres JG, Campbell LM. Follows RMA on behalf of the OPTIONS research group. A controlled assessment of an asthma self-management plan involving a budesonide dose regimen. Eur Respir J 1996;9:886-92.

[27] Mayo PH, Richman J, Harris HW. Results of a program to reduce admissions for adult asthma. Ann Intern Med 1990;112:864-71.

Available online at www.sciencedirect.com
Science 2 Direct・

\section{Copyright General Practice Airways Group Reproduction Prohibited}

